\title{
Transcutaneous bilirubinometry: Influence of gestational age and measurement site
}

\author{
Snehal Vasava ${ }^{1}, *$ Pallavi Parag Dagli ${ }^{2}$ \\ Sri Lanka Journal of Child Health, 2018; 47(1): 27-32
}

\begin{abstract}
Introduction: Neonatal jaundice is the most frequently encountered diagnostic and therapeutic problem in neonates. An estimation of bilirubin is essential for decision making. Transcutaneous bilirubinometer $(\mathrm{TcB})$ is a non-invasive, quick and widely used screening and monitoring tool for the estimation of serum bilirubin.
\end{abstract}

Objectives: To determine correlation and agreement between TcB and total serum bilirubin (TSB) and to verify the influence of different measurement sites for TcB estimation (forehead, sternum and abdomen) in preterm and full-term neonates.

Method: In a prospective study, 306 paired TcB-TSB samples from 306 haemodynamically stable term (150) and preterm (156) infants, up to 14 postnatal days with clinical jaundice were analysed. TcB was measured at the forehead, sternum and abdomen within 5 minutes of blood collection, by a single investigator using Dräger jaundice meter JM-103 device. Linear regression analysis and Bland-Altman plots were used to compare $\mathrm{TcB}$ values at each site with TSB levels.

Results: The mean \pm standard deviation (SD) for gestational age, birth weight and postnatal age were: $35.22 \pm 2.56$ weeks, $2017 \pm 0.59 \mathrm{~g}$ and $96.21 \pm 68.2$ hours respectively. The mean $\pm \mathrm{SD} \mathrm{TcB}$ at different sites were; forehead $13.46 \pm 4.32$, sternum $13.33 \pm 4.38$ and abdomen $11.88 \pm 4.27 \mathrm{mg} / \mathrm{dl}$. The mean $\pm \mathrm{SD}$ TSB was $15.59 \pm 5.93 \mathrm{mg} / \mathrm{dl}$. TcB significantly correlated with TSB at all three measurement sites $(p<0.001)$.

${ }^{1}$ Baroda Medical College, Baroda, India, ${ }^{2}$ SMT NHL Municipal Medical College, Ahmedabad, India

*Correspondence: paragpallavi2000@gmail.com

(Received on 04 April 2017: Accepted after revision on 29 May 2017)

The authors declare that there are no conflicts of interest

Personal funding was used for the project.

Open Access Article published under the Creative

Commons Attribution CC-BY (CC)
The correlation coefficient (r) among the sites were: forehead: 0.88 , sternum: 0.88 , and abdomen: 0.86 . Bland-Altman plot showed significant agreement between TcB and TSB in both preterm and term neonates at all three measurement sites.

Conclusions: The TcB levels can accurately predict TSB in both preterm and term neonates and also at all measurement sites viz. forehead, sternum and abdomen.

DOI: http://dx.doi.org/10.4038/sljch.v47i1.8426

(Key words: Neonatal jaundice, indirect hyperbilirubinaemia, JM-103 device, transcutaneous bilirubinometry, total serum bilirubin)

\section{Introduction}

Approximately $85 \%$ of all term newborns and most premature infants develop clinical jaundice ${ }^{1}$. Three methods are used to estimate the bilirubin level in the neonate viz. visual assessment (VA), transcutaneous bilirubin (TcB) and measurement of the total serum bilirubin (TSB). Many neonatal jaundice guidelines have shown that VA is subjective, inaccurate and not a reliable indicator of the $\mathrm{TSB}^{1,2,3}$. The measurement of the TSB remains the gold standard but this is invasive, painful and time-consuming. $\mathrm{TcB}$ is an alternative to measurement of the TSB and has been validated for clinical use through extensive study. It can reliably estimate serum bilirubin level independent of the skin pigmentation, postnatal age and weight of the infant and can be used as a screening tool ${ }^{1}$. It has the potential to reduce the number of invasive tests performed in the newborn and reduce health care costs ${ }^{1,3}$. TcB may be more useful in the vulnerable preterm population because of the serious and prolonged course of jaundice and higher predisposing factors requiring more frequent bilirubin measurements.

\section{Objectives}

The aims of our study were to determine correlation and agreement between TcB and TSB and to verify the influence of different measurement sites for $\mathrm{TcB}$ estimation (forehead, sternum and abdomen) in preterm and full-term neonates. 


\section{Method}

This was a prospective study conducted from August 2012 to July 2013 in the neonatal intensive care unit (NICU) and maternity ward in a tertiary care teaching hospital, Ahmedabad, Gujarat. The study protocol was approved by the institutional ethical committee. The newborns were included in the study only if visual observation of jaundice raised concern for risk of hyperbilirubinaemia. Haemodynamically stable, 306 term and preterm infants with grossly uniform skin colour and up to 14 days postnatal age were recruited after obtaining parental consent. A total of 306 paired TcB-TSB samples, only of first examination in order to acquire only one data set per infant, were analysed. For preterm infants recruited later, corrected gestational age was taken into consideration. Patients having major congenital malformations, bleeding disorder, direct hyperbilirubinaemia or local skin condition (e.g. oedema, infection) were excluded from the study. Patients who had received phototherapy or exchange transfusion were also not included.

All TcB measurements were done using Dräger jaundice meter JM-103 by a single investigator in accordance with the manufacturer recommendation. The JM-103 does not require user calibration. Reproducibility of the light output of the device was tested daily using the checker. For all $\mathrm{TcB}$ measurements, an average of 3 consecutive scans recorded in a quiet infant at 3 second intervals, was considered as the TcB level in $\mathrm{mg} / \mathrm{dl}$. The TcB measurements at 3 different sites; forehead, midsternum \& lower abdomen were recorded for each infant. Blood samples for TSB were drawn from peripheral veins within 5 minutes of $\mathrm{TcB} \&$ analysed within 30 minutes by spectrophotometry (Abbot Architect C 8000) in a single laboratory.

Demographic data, TcB and TSB values were analysed using SPSS version 20. The correlation coefficient (r) between TcB and TSB was calculated using Pearson's Linear Regression. Sensitivity and specificity of TcB values in $1 \mathrm{mg} / \mathrm{dl}$ increment were analysed in relation to various TSB levels. The $p$ value $<0.05$ was considered statistically significant. The regression equation and coefficient of determination $\left(\mathrm{R}^{2}\right)$ were calculated using the results between the TcB and TSB values. Bland-Altman plots (mean $\pm 1.96 \mathrm{SD}$ ) were used to determine the difference between TcB and TSB at each body site and for preterm and term neonates.

\section{Results}

A total of 306 newborns having indirect hyperbilirubinaemia and their 306 TcB-TSB paired samples in the first 14 days of life were studied. Demographic characteristics of subjects are shown in table 1.

Table 1: Demographic characteristics $(n=306)$

\begin{tabular}{|l|c|}
\hline \multicolumn{1}{|c|}{ Characteristic } & No. $(\%)$ \\
\hline Birth weight $(\mathrm{g})$ & $05(01.6)$ \\
$1000-1499$ & $36(11.8)$ \\
$1500-2499$ & $146(47.7)$ \\
$\geq 2500$ & $119(38.9)$ \\
\hline Gestational age (weeks) & \\
$<28$ & $03(01.0)$ \\
$28-31$ & $31(10.2)$ \\
$32-36$ & $122(39.8)$ \\
$37-41$ & $150(49.0)$ \\
$>41$ & $0(0)$ \\
\hline Underlying cause of indirect & \\
hyperbilirubinaemia & $132(43.1)$ \\
Physiological jaundice & $19(06.3)$ \\
Unspecified jaundice & $03(01.0)$ \\
Enclosing haemorrhage & $53(17.3)$ \\
ABO incompatibility & $31(10.1)$ \\
Rh incompatibility & $68(22.2)$ \\
Septicaemia & $187(61.1)$ \\
\hline Age at the time of measurement & $108(35.2)$ \\
0 - 96 hours & $11(03.7)$ \\
5 - 9 day of life & \\
10 - 14 day of life &
\end{tabular}

In this study $150(49 \%)$ neonates were full-term and $156(51 \%)$ were pre-term. Mean \pm standard deviation (SD) for gestational age, birth weight and postnatal age were $35.22 \pm 2.56$ weeks, $2017 \pm 0.59 \mathrm{~g}$ and $96.2 \pm$ 68.2 hours. Mean $\pm \mathrm{SD}$ for $\mathrm{TcB}$ at different sites were: forehead $13.46 \pm 4.32$, sternum $13.33 \pm 4.38$ and abdomen $11.88 \pm 4.27 \mathrm{mg} / \mathrm{dl}$. Mean $\pm \mathrm{SD}$ for TSB was $15.59 \pm 5.93 \mathrm{mg} / \mathrm{dl}$.

Linear regression analysis between $\mathrm{TSB}$ and $\mathrm{TcB}$ measurements obtained from 3 different measurement sites have been represented in Figure 2. 


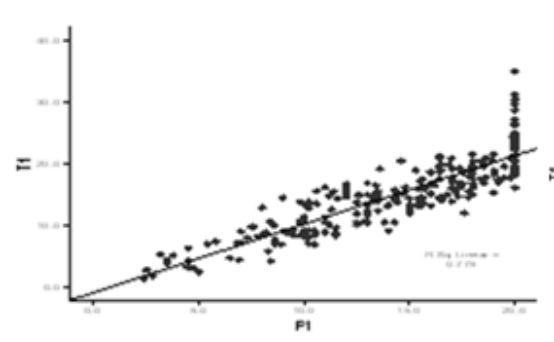

(a)

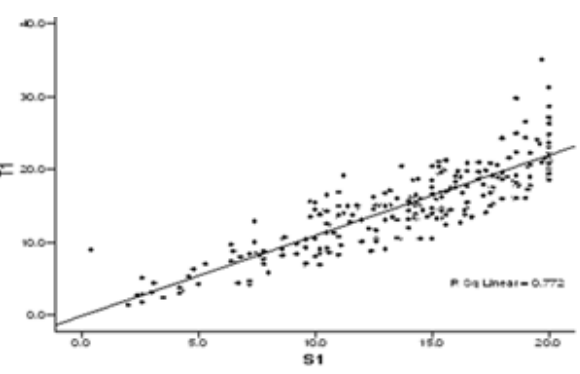

(b)

$\mathrm{TSB}=0.15+1.10 * \mathrm{TcB}$ (sternum) $\mathrm{r}=0.88, \mathrm{R}^{2}=0.772, \mathrm{p}<0.01$ $\mathrm{TSB}=0.93+1.14 * \mathrm{TcB}($ foreh
$\mathrm{r}=0.88, \mathrm{R}^{2}=0.775, \mathrm{p}<0.01$

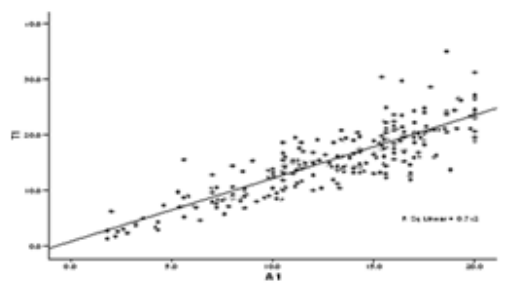

(c)

TSB $=0.88+1.33 * \mathrm{TcB}$ (abdomen), $\mathrm{r}=0.86, \mathrm{R}^{2}=0.742, \mathrm{p}<0.01$

\section{Figure 2: Linear regression analysis between TSB and TcB values for different measurement sites (a) Forehead, (b) Sternum and (c) Abdomen}

The Pearson's correlation coefficient $\mathrm{r}$ for forehead, sternum and abdomen was $0.88,0.88$ and 0.86 respectively. Results showed high correlation $(p<0.01)$ between TSB and TcB for all the three sites, marginally higher for forehead and sternum than abdomen. $\mathrm{R}^{2}$ was highest for the forehead (0.775), followed by the sternum (0.772) and then lower abdomen (0.742). Based on the results of regression model, linear regression equations for the relationship between TSB and TcB were developed. For the forehead site it was $\mathrm{TSB}=0.93+1.14 * \mathrm{TcB}$, for sternum $\mathrm{TSB}=0.15+1.10 * \mathrm{TcB}$ and for abdomen was $\mathrm{TSB}=0.88+1.33 * \mathrm{TcB}$.

Figure 3 depicts the agreement between TSB and $\mathrm{TcB}$ for 3 different measurement sites in full term study subjects.
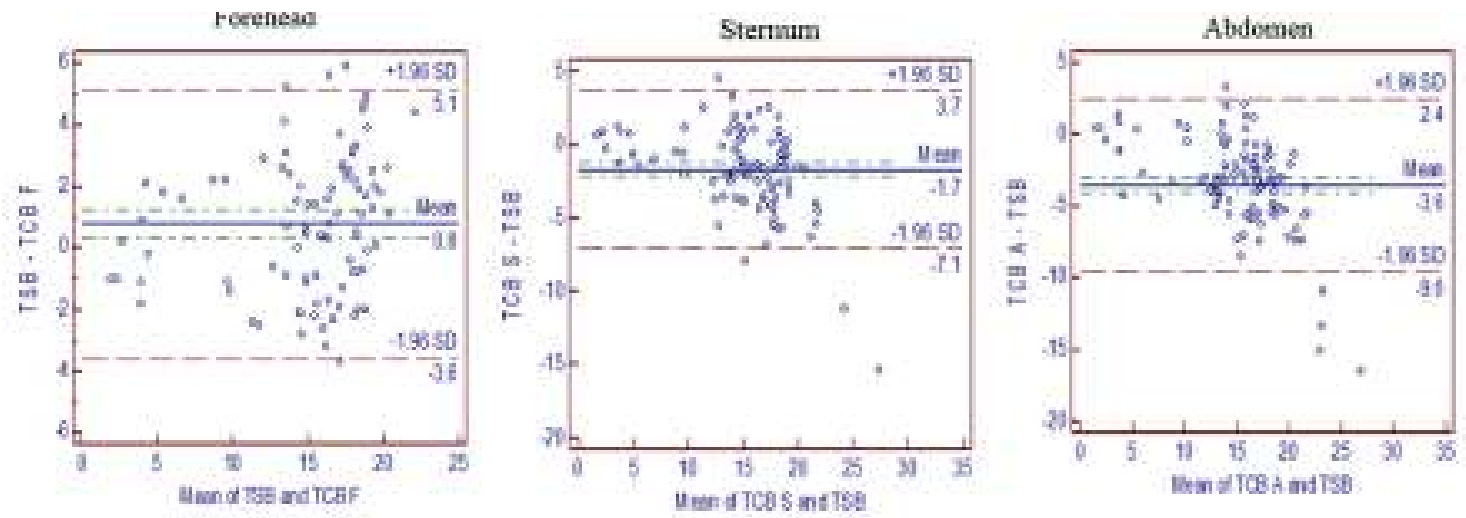

Figure 3: Bland-Altman plot showing agreenent betreen TSB and TCB at 3 different sites in full term study subjects $(n-150)$ 
The mean value of the difference between TSB and TcB values (TcB-TSB) for full term infants, $(n=150)$ at the different sites were: forehead (0.8), sternum (1.7) and lower abdomen (-3.6). The 1.96SD were 4.29 at the forehead, 5.39 at the sternum and 6 at the lower abdomen. The above Bland-Altman plots show that there was very good correlation between the TcB and TSB values in term neonates at all three sites of measurements.

Figure 4 depicts the agreement between TSB and $\mathrm{TcB}$ for 3 different measurement sites in preterm study subjects.
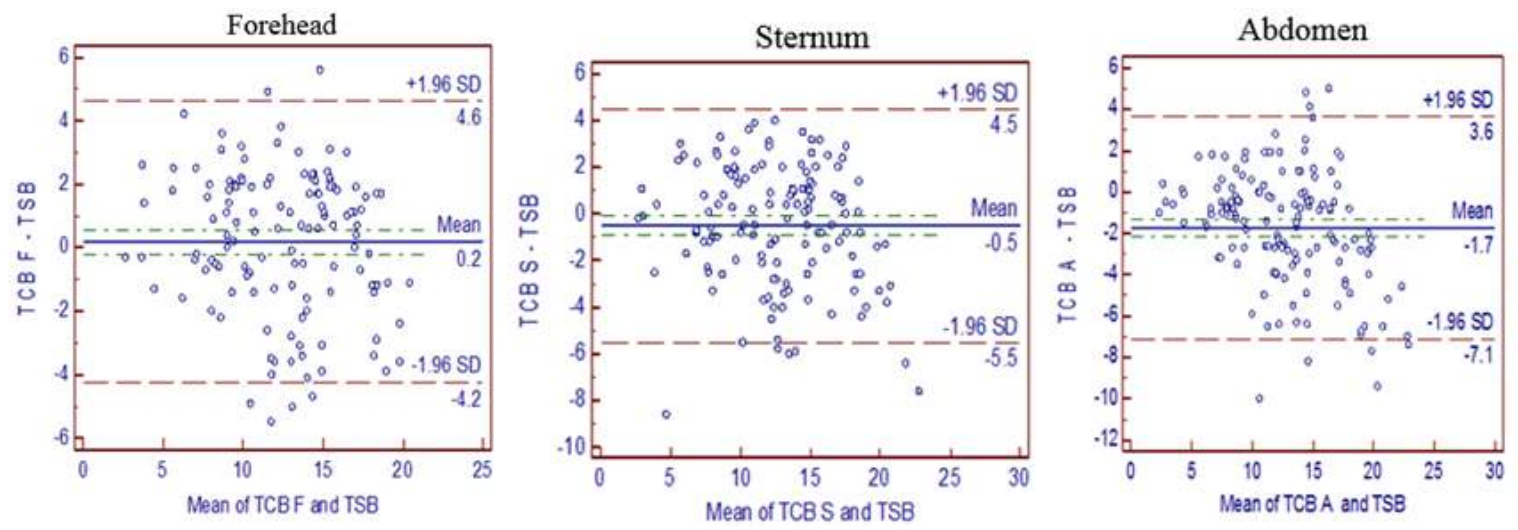

Figure 4: Bland-Altman plot showing agreement between TSB and TcB at 3 different sites in preterm study subjects $(n=156)$

The mean value of the difference between TSB and TcB values (TcB-TSB) for preterm infants, $(n=156)$ at the different sites were: forehead (0.2), sternum ($0.5)$ and lower abdomen (-1.7). The 1.96 SDs were 4.39 at the forehead, 5 at the sternum and 5.29 at the lower abdomen. The above Bland-Altman plots show that there was very good correlation between the TcB and TSB values in preterm newborns.

\section{Discussion}

Identification of newborn at risk of developing significant hyperbilirubinaemia and prevention of bilirubin encephalopathy remains a high priority amongst public health institutions. TcB is widely used as a screening tool and world over many studies have shown good agreement with laboratory measurements. Our study reconfirms a good correlation between TcB and TSB measurements and adds to the available knowledge in that it provides data on all the three measurement sites in all gestational age groups. Most of the researchers have studied specific GA group and measurement sites; forehead and/or sternum. We could not find any study comparing $\mathrm{TcB}$ at all the three sites in both term and preterm Indian neonates. Our study showed accuracy for all the three sites, marginally higher correlation on forehead and sternum than abdomen $(\mathrm{r}$ of 0.88 and 0.88 vs 0.86 ).
Study by Chawla et al in 256 preterm neonates of $<35$ weeks GA for all 3 sites showed good correlation on forehead followed by abdomen and then sternum $(r=0.84,0.72 \text { and } 0.83)^{4}$. Similar observations have been made by Kurokawa et al in VLBW neonates 5 . The studies by Stillova et al also showed $(\mathrm{r}=0.85$, 0.81 and 0.73$)$ and $(\mathrm{r}=0.81,0.93$ and 0.87$)$ over forehead, sternum and abdomen in 44 neonates of 3234 GA group and 32 neonates of $<32$ GA respectively ${ }^{6,7}$. We speculate that the $\mathrm{TcB}$ measurement technique is not stable and consistent at the lower abdomen because abdomen is too soft in neonates, particularly tiny preterms. Forehead may be a more convenient site and better correlates with TSB, but skin over sternum may be typically light protected and therefore show greater correlation $^{8,9,10,11}$. Recent systematic review of absolute TcB-TSB difference plots in preterms revealed minimal bias in measurement irrespective of site with pooled estimates of $0.83^{12}$. Literature review of multiethnic cohort by Peter et al concluded that forehead is better than sternum for Indian neonates $(r=0.934 \text { vs } 0.914)^{13}$. Mahajan et al also found correlation coefficient of 0.878 and 0.859 at forehead and sternum respectively in GA ranging from 28 to 42 weeks $^{14}$.

Our study revealed significant correlation between $\mathrm{TcB}$ and TSB for both preterm and term infants. Few 
other studies have found positive correlation in both preterm and term neonates ${ }^{15,16,17}$. In contrast, Bela et al and Mahajan et al found correlation only in term neonates with $\mathrm{r}=0.85 \quad(0.34$ and 0.45 in two preterm groups) and $\mathrm{r}=0.83$ ( 0.31 in preterm) respectively ${ }^{14,18}$. Evidence from 34 screening accuracy studies in GA of $\geq 35$ indicated a strong correlation between TcB \& $\mathrm{TSB}$ with a correlation coefficient ranging from 0.75 to $0.95^{2}$. Bental et al also concluded $\mathrm{r}=0.846$ from 1091 paired measurements from 628 infants after mean of the forehead and sternum measurements in term and near term neonates ${ }^{19}$. Systematic review by Zhang comparing TcB-TSB nomograms stated same predictive value and both could be used to identify subsequent significant hyperbilirubinemia ${ }^{20}$. Several others, including some Indian studies targeting term babies had also shown agreement ${ }^{2,8,13,21}$.

For preterm babies, studies focusing on different GA groups ranging 24-36 weeks showed high TcB-TSB correlation ranging from $0.79-0.93^{6,7,9,13,15,22,23}$. De luca et al recently performed a meta-analysis of available literature and showed high correlation and global Pearson's r=0.84 (95\% CI: $0.79-0.87)^{24}$. Recent systematic review on reliability of $\mathrm{TcB}$ devices in preterm infants gathered results of 21 studies showed pooled estimates of $\mathrm{r}=0.89$ in $<32 \mathrm{GA}$ and concluded that $\mathrm{TcB}$ devices could be used in preterm neonates to reduce blood sampling ${ }^{12}$. Limitation of the study was under representation of extremely preterm neonates.

\section{Conclusions}

The TcB levels can accurately predict TSB in both preterm and term neonates and also at all measurement sites viz. forehead, sternum and abdomen.

\section{Acknowledgments}

We are thankful to Dr. Sonal Shah, department of community medicine, Smt. NHL MMC for her statistical assistance.

\section{References}

1. Cloherty, JP, Eichenwald EC, Hansen AR, Stark A. Manual of Neonatal Care. 7 th ed. New Delhi: Wolters Kluwer, 2015 Ch. 26 P 304-309.

2. Institute of Health Economics. Transcutaneous bilirubinometry for the screening of hyperbilirubinaemia in neonates $\geq 35$ weeks' gestation. Edmonton AB: Institute of Health Economics, Alberta, Canada, 2013.
3. American Academy of Pediatrics Subcommittee on Hyperbilirubinemia. Management of hyperbilirubinaemia in the newborn infant 35 or more weeks of gestation. Pediatrics 2004; 114(1):297-316. https://doi.org/10.1542/peds.114.1.297 PMid: 15231951

4. Chawla D, Jain S, Kaur G, Sinhmar V, Guglani V. Accuracy of transcutaneous bilirubin measurement in preterm low-birth-weight neonates. European Journal of Pediatrics 2014; 173(2):173-9.

https://doi.org/10.1007/s00431-013-2142-0

PMid: 23955487

5. Kurokawa D, Nakamura H, Yokota T, Iwatani S, Morisawa T, Katayama Y, et al. Screening for hyperbilirubinaemia in Japanese very low birthweight infants using transcutaneous bilirubinometry. Journal of Pediatrics 2016; 168:77-81.

https://doi.org/10.1016/j.jpeds.2015.08.038

PMid: 26410797

6. Stillova L, Matasova K, Mikitova T, Stilla J, Kolarovszka H, Zibolen M. Evaluation of transcutaneous bilirubinometry in preterm infants of gestational age 32-34 weeks. Biomed Pap Med Fac Univ Palacky Olomouc Czech Repub 2007; 151:267-71.

https://doi.org/10.5507/bp.2007.045

PMid: 18345262

7. Stillova L, Matasova K, Zibolen M, Stilla J, Kolarovszka H. Transcutaneous bilirubinometry in preterm neonates. Indian Pediatrics 2009; 46(5):405-8.

PMid: 19179735

8. Engle WD, Jackson GL, Engle NG. Transcutaneous bilirubinometry. Seminars in Perinatology 2014; 38:438-51. https://doi.org/10.1053/j.semperi.2014.08.007 PMid: 25282473

9. Sajjadian N, Shajari H, Saalehi Z, Esphahani F, Alizadeh Taheri P. Transcutaneous bilirubin measurement in preterm neonates. Acta Med Iran 2012; 50(11):765-70.

PMid: 23292629

10. Rubaltelli FF, Gourley GR, Loskamp N, et al. Transcutaneous bilirubin measurement:a 
multicenter evaluation of a new device. Pediatrics 2001; 107(6):1264-71.

https://doi.org/10.1542/peds.107.6.1264

PMid: 11389241

11. Conceicao CM, Dornaus MF, Portella MA, Deutsch AD, Rebello CM. Influence of assessment site in measuring transcutaneous bilirubin. Einstein (Sao Paulo) 2014; 12: 11-15. https://doi.org/10.1590/S167945082014AO2711 PMCid: PMC4898232

12. Nagar G, Vandermeer B, Campbell S, Kumar M. Reliability of Transcutaneous Bilirubin Devices in Preterm Infants: A Systematic Review. Pediatrics 2013; 132(5):71-81. https://doi.org/10.1542/peds.2013-1713 PMid: 24127472

13. Peter Kirm Seng Moey. "Transcutaneous bilirubin measurement to estimate serum bilirubin in neonates in a multi-ethnic cohort: A literature review". Proceedings of Singapore Healthcare 2016; 26(1): 42-57. https://doi.org/10.1177/2010105816665854

14. Mahajan G, Kaushal RK, Sankhyan N, Sharma RL, Nakra M: Transcutaneous bilirubinometer in assessment of neonatal jaundice in northern India. Indian Pediatrics 2005; 42:41-5. PMid: 15695857

15. Afanetti M, dit Trolli SE, Yousef N, Jrad I, Mokhtari M. Transcutaneous bilirubinometry is not influenced by term or skin color in neonates. Early Human Development 2014; 90(8):417-20. https://doi.org/10.1016/j.earlhumdev.2014.05.00 9

PMid: 24951079

16. Yasuda $\mathrm{S}$, Itoh $\mathrm{S}$, Isobe $\mathrm{K}$, et al. New transcutaneous jaundice device with two optical paths. Journal of Perinatal Medicine 2003; 31(1):81-8.

https://doi.org/10.1515/JPM.2003.012

PMid: 12661149

17. Mahmood I, Taghi HTM, Mehdi M. Transcutaneous bilirubinometry compared with serum level of bilirubin in icteric neonates in Zahedan. Journal of Medical Sciences 2005; 5: 239-42.

https://doi.org/10.3923/jms.2005.239.242
18. Shah B, Dhara Gosai D, Prajapati J. Comparison study between serum and transcutaneous bilirubin measurement with special reference to gestational age. International Journal of Science and Research 2015; 4(1): 2250-3.

19. Bental YA, Shiff Y, Dorsht N, Litig E, Tuval L, Mimouni FB. Bhutani-based nomograms for the prediction of significant hyperbilirubinaemia using transcutaneous measurements of bilirubin. Acta Paediatr 2009; 98:1902-8. https://doi.org/10.1111/j.16512227.2009.01385. $\mathrm{X}$

PMid: 19508300

20. Yu ZB, Han SP, Chen C. Bilirubin nomograms for identification of neonatal hyperbilirubinaemia in healthy term and latepreterm infants: a systematic review and metaanalysis. World Journal of Pediatrics 2014; 10:211-8. https://doi.org/10.1007/s12519-014-0495-8 PMid: 25124971

21. Mansouri M, Mahmoodnejad A, Taghizadeh Sarvestani R, Gharibi F. A comparison between transcutaneous bilirubin $(\mathrm{TcB})$ and total serum bilirubin (TSB) measurements in term neonates. International Journal of Pediatrics 2015; 3(1): 633-41.

22. Alsafadi TM, Alsaedi SA. The accuracy of transcutaneous bilirubin measurements in preterm infants. Journal of Clinical Neonatology 2015; 4:18-21.

https://doi.org/10.4103/2249-4847.151160

23. Schmidt ET, Wheeler CA, Jackson GL, Engle WD. Evaluation of transcutaneous bilirubinometry in preterm neonates. Journal of Perinatology 2009; 29(8): 564-9. https://doi.org/10.1038/jp.2009.38 PMid: 19322191

24. De Luca D, Zecca E, de Turris P, Barbato G, Marras M, Romagnoli C. Using BiliCheck for preterm neonates in a sub-intensive unit: diagnostic usefulness and suitability. Early Human Development 2007; 83(5):313-7. https://doi.org/10.1016/j.earlhumdev.2006.06.00 6

PMid: 16949773 